\title{
Bullying in the health service
}

John Launer

If you ever thought that training through humiliation and intimidation was something from a bygone age, think again. In some places it is the norm. The last annual survey of junior doctors conducted by the General Medical Council (GMC) showed that bullying was a problem in up to 40 per cent of units within hospital trusts in some regions of the United Kingdom. ${ }^{1}$ According to the Chartered Institute of Personnel, bullying is 'persistent behaviour that is intimidating, degrading, offensive or malicious and undermines the self-esteem of the recipient.' This definition is helpful because it emphasises persistence. Any of us may lose our temper on occasion and say unfortunate things, but in calmer moments we regret this and apologise, and in general our behaviour is more civilised. With bullying, by contrast, perpetrators behave in a way that is habitually unacceptable without recognising the need to make amends. Undermining is an important aspect of bullying because it affects people's own view of themselves and reduces their self-confidence.

Bullying takes many forms. At its most obvious, it can involve shouting, sarcasm, mockery, belittling, inappropriate jokes and public criticism. It can also take subtler but equally harmful forms. These include always giving negative feedback, making demands on people beyond their level of training, imposing an unreasonable workload on them, or storing up criticism and then expressing it all at one time. When people are bullied on account of their gender, ethnic background, religion, sexual orientation or disability, it may reach the threshold for the legal definition of harassment. Bullying can be directed at anyone, but it is commonly aimed at the most vulnerable, including less resilient trainees, and others including nurses, ancillary workers, medical students, staff grade colleagues or even more junior consultants. Any of these people, in some situations, may also turn into bullies themselves.

A team from Durham University, led by Professor Jan Illing, recently published a detailed review of research on bullying in

Correspondence to Dr John Launer, London Department of Postgraduate Medical Education, London Deanery, Stewart House, London WC1B 5DN, UK: jlauner@londondeanery.ac.uk the NHS. ${ }^{2}$ This shows that bullying is a complex problem in terms of both its causes and effects. It involves many different factors. These include individual ones, including the personalities of the bully and victim. The culture of teams has an influence too, so that people may learn to accept harsh criticism as something routine. The most important factors operate at the organisational level. These include the quality of leadership and the climate of the whole institution. The consequences of bullying also occur at a number of different levels. Bullying has an emotional impact on individuals, and on both their mental and physical health. Groups become demoralised, causing high rates of sickness leave and staff turnover. It impacts on the organisation itself, leading to poor performance, reduced productivity, and systemic risks to patient safety. Anyone trying to address bullying needs to understand these levels, and may need access to resources for dealing with each of them.

\section{EFFECTIVE INTERVENTIONS}

From work we have carried out in London over the past couple of years, we know that there are a number of effective interventions to reduce bullying of trainees at the level of hospital units and teams. ${ }^{3}$ These interventions can demonstrably improve results in the GMC trainee survey from one year to the next. However, every solution needs to fit the particular problem, the people involved and the exact circumstances. Although initial reports of bullying may identify only one or two individuals as bullies, this may signify problems across the whole teaching team. Commonly, bullying goes alongside other issues such as workload or clinical supervision. Concerns over bullying are generally accompanied by a fear of the consequences of whistleblowing. As the report by Robert Frances into the Mid Staffordshire Hospital showed, a climate of intimidation and brutalisation may pervade an entire system. ${ }^{4}$

A good place to start is with some candid conversations. Clinicians on the ground may avoid talking directly about the problem, even though everyone knows about it. Trainees may put up with one or two consultants who have longstanding reputations for humiliating juniors, because no-one has ever succeeded in changing their behaviour in the past. The perpetrators almost certainly will not see themselves as bullies but merely as assertive clinicians who are maintaining traditional standards. The consultant group as a whole may grumble that juniors nowadays have unrealistic expectations, or that placements in their hospital are unpopular for reasons beyond their control (like location or high workload) so that their trainees are the less able ones who cannot find jobs elsewhere. They may blame the problem on shift working or shorter hours, even though other units have adapted well to these. Such simplistic narratives need to be challenged. There is always another side to the story. Opening up these claims for discussion-among trainees, trainers, or both — can start to make a difference. Problems that seemed unmentionable and intractable start to budge.

\section{NEED TO CHANGE}

In our experience, even the most recalcitrant bullies sometimes recognise they need to change. They may accept training, mediation, coaching or psychological help. If not, they can be redeployed away from training or even face grievance procedures or disciplinary proceedings. Consultant groups can engage in dialogue with trainees over differing expectations, receive training in how to deal with challenging juniors, and work with trainee representatives to establish better relations on the unit. The key in every case seems to be that someone-a director of medical education, a training programme director, a clinical lead or even a single educational supervisor-believes that bullying can be challenged, and changed. Sometimes it is only the threat of losing training placements that acts as a spur for this to happen. Perhaps this is not the ideal way of concentrating people's minds on the problem, but there are worse ways, such as trainees actually being withdrawn because of complaints. Increasingly, this threat is actually put in to practice, as it should be if the problem persists and no-one does anything about it.

In the end, the biggest difference occurs when change happens at the top of the organisation. As the report from Durham University points out, many organisations have a lengthy and sonorous anti-bullying policy, but fail to follow this through. The biggest deterrent to change is when senior people are seen to get away with abusive behaviour. If the chief executive and medical director regularly shout at people or threaten them for not reaching 
targets, it is hard to persuade people further down in the hierarchy to behave differently. Conversely, where leaders model respectful interactions, they see this mirrored throughout the institutions they lead. One of the most important lessons from the Mid Staffordshire Inquiry was that the shameful care and needless deaths that occurred on the wards and in the operating theatres were inseparably linked to 'incentivising short cuts to compliance by applying career-threatening pressure'or, in plain language, bullying people. It is at the top level that candid conversations are most needed. We should not be afraid of having them.

Competing interests None.

Provenance and peer review Commissioned; internally peer reviewed.

To cite Launer J. Postgrad Med J 2013;89:307-308.

Postgrad Med J 2013;89:307-308.

doi:10.1136/postgradmedj-2013-131983

\section{REFERENCES}

1 General Medical Council. National training survey. London: General Medical Council, 2012. http://www. gmc-uk.org/education/surveys.asp (accessed 24 Mar 2013).
2 Illing JC, Carter M, Thompson NJ, et al. Evidence synthesis on the occurrence, causes, consequences, prevention and management of bullying and harassing behaviours to inform decision making in the NHS. Durham: Durham University, 2012. http://www.netscc ac.uk/hsdrffiles/project/SDO_FR_10-1012-01_V06.pdf (accessed 7 Feb 2013).

3 London Deanery. Support for educational teams. London: London Deanery, 2013. http://www.faculty. londondeanery.ac.uk/educational-team-development (accessed 23 Mar 2013).

4 Mid Staffordshire NHS Foundation Trust Public Inquiry. Report of the Mid Staffordshire NHS foundation trust public inquiry. London: The Stationery Office, 2013. http://www.midstaffspublicinquiry.com/report (accessed 23 Mar 2013). 